\title{
Recensão crítica do livro "Etnografia e intervenção social - por uma praxis reflexiva",
}

\author{
Hermínia Fernandes Gonçalves², UTAD e CETRAD, Portugal
}

O livro Etnografia e Intervenção Social - Por uma Praxis Reflexiva é uma colectânea de artigos que, tal como salientam os seus organizadores na primeira frase da introdução, "flui entre dois pólos: etnografia e intervenção social". Vou começar por me debruçar sobre os autores e a estrutura da obra para, de seguida, sobrevoar as principais ideias, dos vários autores, subjacentes aos vários artigos.

Esta obra conta com Pedro Silva, Octávio Sacramento e José Portela na coordenação e reúne contributos de outros quinze autores, entre os artigos, o prefácio e o posfácio, de que falarei à frente. Com formações avançadas de Antropologia, de Sociologia, de História Contemporânea e de Psicologia, os autores partilham com o leitor as suas experiências e reflexões em torno dos usos e implicações sociopolíticas da Etnografia. Sobre a filiação institucional dos autores destaca-se a reflexão profícua inter-universidades, inter-Centros de Investigação, com investigações etnográficas de contextos nacionais e estrangeiros (Portugal, França, Espanha, Brasil e Estados Unidos). Participam nesta colectânea professores da UTAD, da Universidade do Minho, do ISCTE, da Universidade Nova de Lisboa, da Universidade Complutense de Madrid e da Universidade do Porto. Estão representados, através dos seus investigadores, vários centros de investigação, com maior destaque para o CETRAD e para o CRIA, além do Centro de Investigação em Ciências Sociais (CICS) e do Centro de Investigação e Intervenção Educativa (CIIE). Está também representado o DINÂMIA'CET-IUL - Centro de Estudos sobre a Mudança Socioeconómica e o Território, no prefácio de Isabel Guerra, e a Universidade da Califórnia-Berkeley, no posfácio de Stanley Brandes.

Na senda de concluir sobre a experiência dos vários autores em pesquisa etnográfica, tal como o sublinharam os seus organizadores, "acham-se envolvidos jovens doutorandos e recém-doutorados a docentes investigadores em final de ciclo e até já no gozo da sua reforma. Não surpreende, portanto, que entre os obreiros haja posições variadas quanto à produção e/ou (co)organização de livros" (p.12). Acresce salientar que participam desta obra investigadores premiados, como María Isabel Jociles Rubio, Manuela Ivone Cunha, Fernando Bessa Ribeiro e Octávio Sacramento.

Esta obra é composta por quatro partes. A primeira parte, "Entre a etnografia e os problemas sociais", aplica a investigação etnográfica ao contexto prisional, na prisão de Tires, Portugal, e reflecte sobre as agendas públicas, as agendas de investigação e a prisão como objecto, por Manuela Ivone Cunha; de seguida, chega-nos uma investigação etnográfica sobre o tráfico de mulheres em Portugal, como problema social, por Lourenzo Bordano e Filipa Alvim; esta primeira parte termina com as etnografias visuais: (im)possibilidade de uma antropologia visual aplicada, uma investigação de Humberto Martins. A segunda parte, "Trabalhadores e imigrantes: Precarização para uns, extradição para outros", volta à investigação etnográfica, ora para a "Precarização da população trabalhadora na Lisnave e para as redes de solidariedade na Baixa da Banheira", por Inês Fonseca, ora incidindo nas "Vidas embargadas: a institucionalização temporária de estrangeiros ilegais em Portugal, no contexto das actuais políticas de imigração", por Octávio Sacramento e Manuela Ribeiro. A terceira parte, "Jovens e Mães entre a sexualidade (de risco) e a monoparentalidade", abre caminhos à etnografia em contextos exteriores a Portugal, ora encarando a "Ecologia Social e os comportamentos sexuais de risco de Jovens da

\footnotetext{
${ }^{1}$ Silva, Pedro; Sacramento, Octávio; Portela, José (Coords.) (2011), Etnografia e Intervenção Social - Por uma Praxis Reflexiva. Lisboa, Colibri.

${ }^{2}$ hgoncalves@utad.pt.
} 
região de Île-de-France", por Marta Maia, ora questionando "É a ausência do pai um problema? A dissociação dos papéis paternos entre as mães solteiras", em Madrid, por Maria Isabel Jociles Rubio e Ana Maria Rivas Rivas. A quarta e última parte reflecte o "saber dos investigadores, da pesquisa ao debate político e à intervenção social", e é iniciada com Fernando Bessa num artigo sobre as "Ciências Sociais, autor e participação no espaço público: retomando a proposta de Bourdieu por um saber comprometido"; segue-se Alexandra Oliveira, que aborda a "pesquisa etnográfica sobre a prostituição de rua"; e Telmo Caria, guiado por noções de profissão, conhecimento e reflexividade, "Perspectiva a intervenção social: reflexões e dados empíricos sobre o trabalho profissional e o uso do método etnográfico no terceiro sector". Esta obra termina com chave mestra no posfácio de Stanley Brandes, que nos deixa uma "nota final sobre a etnografia, reflexões para os Estados Unidos".

Do formato metodológico das diferentes investigações etnográficas destaca-se a utilização de um instrumental metodológico diversificado, coerente com os princípios metodológicos propostos em Ciências Sociais. Por inerência do método etnográfico, o uso da observação participante nos contextos naturais é a abordagem dominante. Percebem-se, ao longo da obra, fusões metodológicas, com preocupações de combinação de métodos de trabalho, como histórias de vida, observação participante, etnografia institucional, consulta de fontes secundárias, inquéritos por questionário, entrevistas semi-directivas, conversas informais, entrevistas não estruturadas, observação participante em locais e ocasiões distintas e observação em espaços virtuais.

Antes mesmo de apresentar os caminhos da investigação etnográfica percorridos pelos autores ao longo dos diferentes contextos de investigação, por tudo o que já se disse, sobre a experiência investigativa dos seus organizadores e autores, é hora de felicitar todos aqueles que participaram nesta colectânea, que espelha o mundo real dos contextos abordados. Uma parte significativa dos artigos, além da investigação etnográfica dos contextos, naturalista, de compreensão e descoberta, interroga as potencialidades e os limites da investigação etnográfica para a intervenção social, desde logo, na introdução com José Portela, Octávio Sacramento e Pedro Silva. Também nos artigos de Telmo Caria, Humberto Martins, Fernando Bessa Ribeiro, e Manuela Ivone Cunha. A riqueza do conteúdo da investigação etnográfica leva-nos agora a percorrer as principais ideias deixadas ao leitor, ao longo dos vários artigos.

Manuela Cunha volta-se para instituições prisionais. Começa por pensar a relação entre o problema social e o problema de investigação, concluindo a dada altura, "À investigação que incide sobre terrenos social e politicamente candentes colocam-se, desde logo, problemas relativos à própria construção do objecto (...)." (p.50). A questão da delimitação da unidade de análise e a tendência empirista para fazer coincidir o locus da pesquisa com o objecto de estudo, além dos riscos mais gerais como o de importar directamente "temas" da actualidade sem os reelaborar como problemas de investigação, ou adoptar, como categorias conceptuais, noções pré-fabricadas e pré-recortadas na arena pública sem o necessário distanciamento reflexivo.

A autora procede a algumas recomendações importantes, desde logo, o uso da teoria e da reflexividade epistémica para calibrar a investigação etnográfica e a necessária leitura dos resultados em função do lugar que os seus receptores ocupam num dado contexto. Sublinha que "uma curta alusão ao facto de a sociabilidade prisional não conduzir a uma valorização do estatuto "criminal" pode levar os responsáveis penitenciários a usar este aspecto, absolutamente lateral no conjunto dos resultados de uma investigação, a sustentar que a prisão não tem efeitos perversos sobre a reinserção social dos reclusos e, ainda, que as prisões portuguesas se encontram isentas de problemas." (p.56)

Os resultados desta investigação, tal como a autora salienta, vão para além da descrição analítica dos problemas, desde logo, porque conduzem os técnicos, as organizações e as estruturas sociais à reinterpretação dos resultados, sendo expectável que produzam mudanças.

Lourenzo Bordonaro e Filipa Alvim propõem uma reflexão sobre a construção social do tráfico de mulheres enquanto problema social em Portugal. Explicitando as dimensões e as características do tráfico, apresentam-nos o tráfico como problema social com prioridade na agenda política nacional, e reflectem sobre o modo como isso tem influenciado o sector da investigação científica, os operadores do sector da ajuda social, os técnicos e assistentes sociais, e os órgãos policiais (p.61). 
Os autores, no seguimento de uma abordagem construtivista, na qual o cientista foca o modo como as pessoas definem os problemas e encara o problema como produzido e construído através das actividades sociais, combinam a análise do contexto político da produção do conhecimento sobre o tráfico de mulheres em Portugal com a etnografia institucional, através da realização de entrevistas a organizações estatais e órgãos de polícia criminal. Sobrevoam o interesse político e institucional sobre a questão do tráfico, o estado teórico sobre o tráfico de mulheres em Portugal e a ambiguidade da questão do consentimento, concluindo que os vários quadros teóricos procedem a um debate contínuo entre diferentes interpretações, opiniões e perspectivas.

Das entrevistas com os actores emerge, por um lado, a percepção do tráfico de mulheres como um fenómeno significativo e preocupante e, por outro lado, a percepção de que grande parte das situações de prostituição dificilmente se pode configurar como situações de tráfico de mulheres. Das conclusões retira-se ainda a ideia que as pessoas envolvidas, a nível político e legislativo, no combate ao tráfico em Portugal, raramente tiveram contacto directo com vítimas, "extraem o seu conhecimento acerca do tráfico a partir do que é produzido noutros contextos nacionais, de relatórios internacionais ou da produção científica realizada" (p.74) e elaboram estratégias de cima para baixo. Quanto mais as entrevistas se dirigiram a técnicos ou pessoas que estavam perto do terreno, da situação real das mulheres e das prostitutas, tanto mais o conceito de tráfico parecia opaco, confuso, pouco útil, com contornos dificilmente definíveis. "O conceito era interpretado de forma muito elástica pelos operadores, ou era até confundido com outras práticas. Se na maioria dos casos, de facto, os entrevistados admitiam nunca ter tido contacto com vítimas de tráfico, outros chegaram mesmo a questionar as definições e os números propostos a nível internacional.” (p.74)

Em conclusão, Lourenzo Bordonaro e Filipa Alvim sublinham o carácter abstracto da noção e põem o dedo na ferida ao considerarem o paradigma de tráfico, a partir de uma motivação ideológica, política e policial, como importado pelos locais a partir de cima e aplicado nos contextos como quadro interpretativo. "Assistimos aqui a um procedimento às avessas. Leis, planos e instrumentos de intervenção precedem o crime, não são consequência directa dele, da vontade de lutar contra um fenómeno palpável e observável, quotidianamente encontrado no contexto nacional." (p.78)

Humberto Martins reflecte sobre a antropologia visual em dois campos teórico-práticos, o da antropologia sensorial e o da antropologia aplicada. Propõe o documentário, com breves referências às fotografias, como produto audiovisual baseado numa cinematografia do real e advoga uma desconvencionalização do uso das imagens, dando aso a novas interdisciplinaridades e a novos produtos, em ciências sociais e na intervenção social.

Munido da teoria sobre as (in)definições da antropologia visual como um campo teórico-prático da Antropologia Social e Cultural, procede a questionamentos que nos remetem para a aplicabilidade da Antropologia. A perspectiva de Humberto Martins pende para uma antropologia visual que explore novas possibilidades de conhecer (enquanto técnica e metodologia) e o repensar do estatuto epistemológico do conhecimento e das formas de representação antropológicas. O autor estabelece os limites e ambiguidades de uma antropologia aplicada, com ou sem imagens, mas reconhece que os processos de intervenção com imagens têm inerente (quase sempre) um propósito de mudança social. O autor, utilizando como exemplo a intervenção em âmbito hospitalar, provoca a reflexividade do leitor, a partir das seguintes perguntas: "pode um médico filmar um doente em estado terminal? Pode um antropólogo filmar um doente em estado terminal? Pode um antropólogo filmar um médico a tratar um doente em estado terminal (...)?” (p.104)

O autor salienta que "as respostas a estas perguntas devem ser, obviamente, contextualizadas e inscritas em projectos concretos de investigação através dos quais contactamos com pessoas, situações e realidades específicas. Seguramente haverá contextos hospitalares, doentes e casos clínicos que podem ser filmados mesmo a morte." (p.105) Em suma, Humberto Martins propõe uma intervenção social suportada em imagens, trabalhando com aqueles que estudamos ou sobre os quais intervimos.

Inês Fonseca aborda os processos de precarização social e privilegia a observação dos seus efeitos nas famílias e nas redes sociais primárias, tendo como terreno de observação a freguesia da Baixa da Banheira, na margem sul do rio Tejo. Alude às dificuldades motivadas pela situação de salários em atraso e de precarização laboral e à 
forma como cada agregado foi afectado, consoante a estrutura, a configuração e as redes de entreajuda a que pode recorrer. Ao longo da investigação de Inês Fonseca fica claro que, naquele contexto, as pessoas, perante as difíceis condições de vida e a precariedade laboral, por um lado, as insuficientes políticas sociais estatais e a insuficiente assistência social prestada pelas entidades patronais, ao longo de praticamente todo século XX, deram lugar à emergência de uma diversidade de redes de entreajuda e solidariedades alternativas, umas de carácter mais restrito e homogéneo (constituídas pelos familiares mais próximos) e outras de carácter mais alargado e heterogéneo (integradas não só por vizinhos e colegas de trabalho, mas também pelos indivíduos que integram as redes destes, oriundos e pertencentes a outros contextos socioeconómicos).

Esta conclusão sobre as redes informais de entreajuda como a alternativa às redes formais deve ser inscrita num debate teórico sobre o esgotamento destas redes informais de entreajuda. Na mesma linha de Bourdieu (1994) os riscos poderão culminar num programa de destruição metódica de colectivos como a nação, os grupos de trabalho, os sindicatos e até a família.

Octávio Sacramento e Manuela Ribeiro incidem sobre a gestão da imigração ilegal em Portugal, identificando a fileira desde as acções de intervenção a montante, até à detenção e extradição daqueles que são detectados como imigrantes ilegais no país de destino. A prioridade de análise foi para o modo como os próprios expressam a vivência do processo, e para as consequências que ele desencadeia nos respectivos projectos migratórios. Os autores vão reflectindo sobre os possíveis ajustamentos nas políticas e práticas institucionais que dão corpo à detenção e extradição dos imigrantes no espaço Schengen, uma reflexão enquadrada na constatação "da progressiva transformação do «Espaço Europeu de Liberdade, Segurança e Justiça», cuja génese remonta ao Tratado de Amesterdão, em 1997, num espaço meramente securitário" (p.143). Por outro lado, percebe-se nos autores a clara preocupação de inscrever a imigração num acto de procura de melhores condições de vida por parte de indivíduos que querem aceder às oportunidades da globalização.

Segundo Octávio Sacramento e Manuela Ribeiro, "os centros de detenção temporária de imigrantes constituem, como ficou dito, parte integrante das designadas «hard-line immigration policies» (Russel, 2006), que as lideranças da generalidade dos países, sobretudo os mais desenvolvidos, têm vindo a adoptar como meios de contenção e de regulação do progressivo crescimento da presença de migrantes internacionais, mais em particular dos que chegam em busca de trabalho e de melhores condições de vida" (p.167). Pese embora a legislação nacional e europeia considere a imigração ilegal como um delito administrativo, os Centros de Detencção Temporária, aplicam a detenção por períodos de tempo que, no mínimo, se podem estender por vários meses e no máximo não têm limite definido.

Com a criação da Unidade Habitacional de Santo António (UHSA) evita-se o repatriamento coercivo de estrangeiros detectados sem documentos de autorização de permanência no País. A UHSA, de acordo com legislação nacional e com as recomendações internacionais na área dos Direitos Humanos, "põe fïm à detenção, em cadeias comuns, de imigrantes a aguardar o afastamento do país e apresenta-se como um padrão de condições materiais e, sobretudo, de práticas relacionais que a distingue substancialmente da maioria das suas congéneres estrangeiras e a converte mesmo em exemplo de boas práticas" (p.168). Embora se reconheça a existência de um sistema punitivo relativamente aos imigrantes ilegais, este sistema não tem impedido os imigrantes de tomar a decisão de imigrar, é "a gravidade e a extensão das causas que originam a decisão de emigrar e das circunstâncias que obrigam as pessoas a fazê-lo.” (p.168).

Marta Maia procede a uma investigação etnográfica em torno da compreensão e interpretação de fenómenos sociais como a ecologia social dos comportamentos sexuais de risco em Jovens da Região de Île-de-France. A autora analisou a configuração das representações da sexualidade e dos comportamentos sexuais de indivíduos escolarizados dos 14 aos 20 anos. Comparou populações de meios socioculturais diferentes e escolarizados em dois tipos de estabelecimentos diferentes, dois estabelecimentos públicos (que recebem alunos de diversas origens culturais pertencentes à classe média e de desfavorecidos) e dois estabelecimentos privados (que recebem alunos de origem culturais homogéneas e de classe média alta).

Para a autora, a identidade dos jovens é ajustada pelo capital cultural e simbólico. A educação dada pela família é basilar na medida em que transmite valores e modos de ser e pensar, mas o sistema escolar e os grupos de pares 
redobram a acção dos determinismos sociais e a construção da identidade social e das relações sociais. As representações e as atitudes sobre a sexualidade e sobre os comportamentos sexuais de risco, nomeadamente em relação ao VIH//SIDA, são moldadas pelo contexto sociocultural. Embora estes comportamentos estejam presentes em ambos os grupos observados, apresentam, segundo o estudo, dimensões e razões diferentes. Os alunos dos estabelecimentos públicos "revelam-se insuficientemente informados, sobretudo os mais jovens; não é raro que as relações sexuais ocorram sob o efeito da droga ou do álcool, situação propícia às práticas de risco; e o imperativo da virilidade induz nos rapazes um sentimento de (ilusório) domínio sobre a natureza e sobre o decorrer dos acontecimentos. Por seu turno, os alunos dos estabelecimentos privados, mesmo quando estão bem informados, por beneficiarem anualmente de campanhas de prevenção na escola, sentem-se protegidos pela sua pertença social, tanto mais que recrutam os seus parceiros sexuais no seu próprio meio social, isto é, entre pessoas que estimam serem «de bem» (...).” (pp.181-182)

Há representações que determinam as atitudes, nomeadamente "a seropositividade permanece associada a comportamentos desviantes. Por conseguinte, perante alguém que lhes parece «normal» e «honesto», os adolescentes e jovens não sentem necessidade de se proteger (...).” (p.85) Para uma consciencialização efectiva do risco, a autora sublinha a importância de trabalhar a informação aos jovens alunos, adaptando-a à realidade dos adolescentes, respondendo às suas lógicas e representações. "Em geral, nos estabelecimentos de ensino, a prevenção, quando a há, faz-se no contexto das aulas. Sob esta forma, a informação é sentida como uma intrusão da escola - lugar de desprazer - nas suas vidas íntimas - lugar de prazer - e como um modo demasiado tecnicista de abordar a sexualidade. Os conhecimentos adquiridos no quadro escolar tornam-se, assim, dificilmente transponíveis para a realidade exterior à escola (Maia, 2009). As campanhas de prevenção deveriam realizar-se fora do quadro escolar, para evitar que as informações sejam associadas a um discurso teórico sem ligação à realidade exterior (à escola), à imagem dos conteúdos teóricos escolares" (p.185).

Maria Isabel Jociles Rubio e Ana Maria Rivas Rivas realizam uma investigação etnográfica centrada na Comunidade de Madrid sobre as mães solteiras por opção, cujo foco de análise passa pelo questionamento: é a ausência do pai um problema? As autoras sobrevoam várias teses teóricas sobre o assunto e concluem que os vários quadros teóricos destacam em primeiro lugar a importância que estas mulheres atribuem à figura paternal, seja ela genética ou social.

Esta perspectiva procede a uma desproblematização social da ausência do pai, demonstrando que as mulheres, no decurso do processo, dotam-se de diferentes recursos, dirigidos à normalização dos seus modelos familiares e à apropriação de certas teorias psicológicas, que sustêm a necessidade de uma dupla referencia, a feminina e a masculina. Porém, nas suas percepções, não tem necessariamente de existir coincidência com um pai biológico e/ou um pai social, o referente masculino é o modelo.

Em termos de representações, os relatos apresentam um grau elevado de homogeneização: a) entre as mães adoptivas; e b) entre as mães que optaram pela reprodução sexual com dador conhecido, ou pela reprodução assistida com dador anónimo. Ambas as plataformas conseguiram facilitar às mães a informação e dar-lhes o apoio moral e afectivo, servindo de base para à formação de novas redes sociais, além de as dotar de narrativas que lhes permitem explicar aos seus filhos a ausência da figura paterna, sem considerar este facto um problema.

Fernando Bessa Ribeiro promove um profícuo debate sobre o saber comprometido, assente no binómio ciênciasociedade, no quadro da defesa da legitimidade do uso do conhecimento científico para a emancipação social. A perspectiva do autor segue o paradigma de ciência crítica, partilhado por vários autores, nomeadamente Bourdieu que, assumindo os compromissos teóricos e metodológicos da ciência, não descura os compromissos políticos de emancipação. O autor defende um conhecimento científico capaz de produzir uma eficácia política e social. No quadro da uma sociedade globalizada, com riscos complexos e mutáveis, estão objectivamente convocados os académicos para uma participação no campo da acção política, no sentido lato.

Explicita a necessidade de mobilizar o conhecimento científico para os debates políticos, defende novas políticas e fá-lo suportado nos resultados de duas investigações, uma sobre a prostituição feminina nas regiões de fronteira do norte de Portugal, e outra sobre turismo sexual em Natal, no Brasil. Das conclusões, por um lado, regista-se que, na maioria das vezes, não há relações entre a prostituição feminina e as redes de tráfico e exploração sexual, 
e por outro, as leis repressivas em vigor conduzem a situações abusivas e criminosas. O autor participa em diversas iniciativas públicas que explicitam os riscos e as controvérsias, e esclarecem a prostituição e a defesa da legalização do trabalho sexual.

Ciente das controvérsias resultantes deste posicionamento crítico, designadamente das controvérsias resultantes da subordinação jurídico-funcional às organizações que condicionam a autonomia dos técnicos que aí trabalham, o autor afirma que há "um espaço de manobra, no interior do campo académico-cientifico, para permitir aos antropólogos, aos sociólogos e aos restantes cientistas sociais críticos" (p.240), para colocar sob exame as estruturas hegemónicas. Vai mais longe ao concluir que o "interior destes espaços, de geometria variável, é o espaço adequado para fazer o trabalho crítico de identificação e desconstrução construtiva da actual configuração do mundo em que vivemos e das suas diversas formas de exploração, opressão e dominação" (p.240).

Alexandra Oliveira trabalha a etnografia incidindo sobre a prostituição de rua na cidade do Porto e centra-se na intervenção com pessoas que se prostituem. A autora permaneceu no contexto da prostituição de rua durante um período que totalizou cinco anos. Observou os vários locais de prostituição de rua, sobretudo as pensões na zona central da cidade do Porto, centrou-se no mundo social da prostituição de rua, mas também no mundo familiar de quem a pratica; abarcou os discursos e as trajectórias de vida das mulheres e transgéneros que se prostituem e analisou a reacção social ao acto e aos actores.

A autora identifica problemas nas pessoas que se prostituem na rua que vão desde o estigma e exclusão, decorrentes sobretudo da falta de reconhecimento legal da actividade, às violências, praticadas pelos supostos chulos sobre as prostitutas ou, embora minoritárias, praticadas pelas redes de tráfico e exploração sexual. Concluindo, só em grupos específicos (toxicodependentes, velhas e doentes, transgéneros e imigrantes) existe a necessidade de uma atenção particular.

Embora reconhecendo não ter realizado investigação para acção, esta abordagem etnográfica propõe a aplicação do conhecimento produzido numa intervenção a três níveis:

a. Intervenção para a redução de riscos associados ao trabalho sexual, onde inclui a prevenção e promoção da saúde;

b. Intervenção em grupos específicos com problemáticas particulares não decorrentes do trabalho sexual, onde inclui a intervenção com indivíduos com problemas associados, de toxicodependências, de violência doméstica praticada por chulos, de exploração sexual e os problemas de pobreza e exclusão social relacionados com a velhice e ou patologia mental;

c. Intervenção política, onde inclui o individualismo, a falta de união e de solidariedade, a dificuldade de se assumirem publicamente, a estigmatização e a falta de direitos e a importância de lutar pelos direitos.

A autora integrou os movimentos internacionais de trabalhadores do sexo com a intensão de impulsionar a luta activa pelos direitos destes grupos sociais segue a linha de Zimmerman (1995) e Rappaport (1987), propondo o empoderamento psicológico destes grupos sociais. Sublinha a importância da projecção de uma imagem positiva, o que, conclui, "deve levar a reflectir sobre a necessidade de mudança da perspectiva vitimizadora por parte da sociedade dominante." (pp.266)

Telmo Caria aplica o método etnográfico ao estudo das profissões. Neste artigo, aplica-o especificamente às profissões da intervenção social, restringe-as ao trabalho assalariado, baseado nas ciências humanas e sociais, realizado no terceiro sector por diplomados do ensino superior. Desenvolve uma perspectiva teórico-empírica sobre a noção de intervenção social, considerando-a "um fenómeno social e simbólico que intersecta os conceitos teóricos da profissão, de conhecimento e de reflexividade" (p.272).

$\mathrm{Na}$ sua proposta, a teoria surge como recurso principal (quando existe) para produzir conhecimento legítimo sobre a realidade e, portanto, para o questionamento dos fenómenos sociais. A investigação etnográfica é outro dos elementos, subordinado à necessidade de agir estrategicamente nos contextos e à reflexividade de um saber prático-experiencial. Veja-se, na página 277, “O saber prático experimental também é capaz de gerar 
competências reflexivas para, em contexto (...) se saber como fazer a seguir (...) como categorizar o que ocorre (...) e como ajuizar o que não é esperado que aconteça (...).”

O autor propõe uma conceptualização da intervenção social que contemple a dimensão de acção estratégica, desdobrada em elementos cognitivos e comunicacionais, e uma dimensão de acção comunitária, desdobrada em elementos comunicacionais e normativos que, como demonstra, também dependem dos saberes gerados e reproduzidos na intersubjectividade da acção. Partilha-se do entendimento do autor "as etnografias profissionais tornam-se ferramentas sociocognitivas para entender e explicar a intervenção social, porque, como vimos, através delas os profissionais não só transportam para os seus processos de educação formal as suas interrogações sobre o uso que fazem do conhecimento profissional, como se criam condições metodológicas para produzir conhecimento para a intervenção social e não apenas sobre o objecto intervenção social” (p.287).

Este livro retoma o debate sobre a imersão do investigador no contexto da intervenção social e permite sublinhar as mais-valias da investigação etnográfica para explicitar o contexto como espaço sociocultural, natural, autónomo, diferenciado e específico, e para reflectir teoricamente a prática. No âmbito dos vários artigos exploram-se as relações entre os contextos e a comunidade envolvente, através da observação participante. Subscrevendo Michael Genzuk (1993) a etnografia comporta três princípios metodológicos essenciais: o Naturalismo, que passa pela compreensão do comportamento humano através de um contacto directo em contextos "naturais" e não através de inferências sobre o modo como as pessoas se comportam em ambientes experimentais, ou sobre o modo como se declaram comportar em entrevistas; a Compreensão da cultura do grupo em estudo antes de se avançar com explicações válidas para o comportamento dos seus membros; e, por último, o princípio de Descoberta, um processo indutivo ou baseado na descoberta, em vez de ser limitado pela testagem de hipóteses explícitas. No paradigma actual de ciências sociais, reconhece-se que quem aborda um fenómeno já munido de um conjunto de hipóteses rígidas pode falhar na descoberta da verdadeira natureza desse fenómeno. Não se está a retirar importância às hipóteses, porque, através delas, o foco da investigação concentra-se e torna-se mais preciso para compreender os fenómenos sociais, mas importará flexibilizá-las, ou mesmo mudá-las substancialmente à medida que a investigação avança.

Contudo, quando se trata de relacionar a investigação etnográfica com a intervenção social, a via da compreensão e descoberta dos fenómenos, das suas ambiguidades e fraquezas, ainda que investigados a partir dos contextos naturais, parece insuficiente. A pesquisa pela acção deve desenvolver simultaneamente um trabalho de investigação e uma parceria colaborativa. A comunidade e o pesquisador deverão unir-se com o objectivo de construir um projecto que vise a compreensão dos contextos, da cultura do grupo em estudo. Os objectivos da intervenção deverão resultar desta interacção, informada, entre os diferentes actores, encarando a construção colectiva dos processos, a par com a compreensão e a descoberta das identidades, como parte do processo de etnografia para a intervenção social (Gonçalves, 2011).

O livro Etnografia e Intervenção Social - por uma Praxis Reflexiva, ao longo dos seus artigos, põe em prática as várias funções da pesquisa etnográfica, designadamente as propostas de Genzuk (1993) e Hammersley (1990). Mas, na senda de anexar à função método de conhecimento adequado ao contexto da intervenção social a função de metodologia de investigação-acção, importará tornar o processo de investigação-acção participado, estratégico e eficaz. Com efeito, este livro abre pistas para iniciar ou aprofundar projectos de investigação-acção. Trata-se de uma colectânea que permite aprofundar a análise das questões dos prisioneiros, dos trabalhadores do sexo, das questões da identidade dos sem pai, ou dos profissionais de intervenção social. Por outro lado, sobrevoa conceitos como o de exclusão, saúde, doença, risco, redes, políticas, metodologias.

Por todos os motivos aqui apresentados, este é um livro inspirador para os que pretendem aprofundar o trilho entre a etnografia e a intervenção social. Recomenda-se a sua leitura a todas as áreas das Ciências Humanas e Sociais, directa ou indirectamente, ligadas à intervenção social, com maior destaque ao serviço social.

O assistente social trabalha em contextos sociais, institucionais, culturais, diferenciados. Trabalha com as pessoas, com desigualdades, com exclusões e com riscos. Compete-lhe descobrir, diagnosticar e compreender a identidade colectiva dos actores sociais (um elemento importante no processo de formação de políticas ou processos de intervenção). Compete-lhe promover a constituição de Plataformas de envolvimento dos actores 
sociais, em torno de agendas comuns, programas ou acções de resposta aos problemas (um elemento fundamental à contextualização sistémica e reflexionada). Compete-lhe a mediação e a acção política de suporte social e de mudança, "traduzindo" interesses e valores dos diversos beneficiários, das políticas e dos recursos que se defrontam em espaços públicos. Negociando soluções com o cliente, com a comunidade ou com determinados grupos sociais. Neste sentido, a etnografia, enquanto método de investigação-acção, permitirá ao assistente social descobrir e compreender as verdadeiras necessidades de cada um desses grupos sociais, respeitando os contextos e as identidades. À medida que recolhe, organiza e trabalha a informação, estimula, junto dos seus públicos, a reflexividade, a aprendizagem e o empoderamento. Por outro lado, o método etnográfico, quando aplicado na prática profissional do assistente social, oferece garantias de produção de conhecimento para a intervenção social e não apenas sobre o objecto.

Com efeito, as políticas públicas - sejam elas universais, segmentares, ou específicas - nomeadamente as redistributivas, directamente ligadas ao modelo económico e político de sociedade, implicam uma intervenção social estratégica, suportada em diagnósticos coerentes com os problemas - específicos, multidimensionais e contextualizados - e na (re)programação dos cursos de acção, envolvendo as pessoas, os técnicos e as instituições. A pesquisa etnográfica é sem dúvida um caminho para esta abordagem de investigação pela acção. Por outro lado, a investigação etnográfica, quando realizada pela acção, permite explorar a componente negocial, colectiva, democrática, a capacidade de integração das diversidades culturais, bem como a articulação de agendas, de recursos e políticas, necessários à acção estratégica.

\section{BIBLIOGRAFIA}

Bourdieu, P. (1994), Raisons Pratiques. Sur la Théorie de l’Action, Paris: Seuil.

Genzuk, M. (1993), “A Synthesis of Ethnographic Research”, Occasional Papers Series, Center for Multilingual, Multicultural Research, Rossier School of Education, Los Angeles: University of Southern California.

Gonçalves, H. (2011), "Estratégias Colectivas de Governação Local no Campo Social: alcances e limites. Estudo Sociológico Comparativo", Tese de Doutoramento, Salamanca: USAL.

Hammersley, M. (1990), Reading Ethnographic Research: A Critical Guide, London: Longman.

Zimmerman, M. A. (1995), "Psychological empowerment: issues and illustrations", American Journal of Community Psychology, 23, pp. 581-600.

Rappaport, J. (1987), "Terms of empowerment/exemplars of prevention: toward a theory for community psychology", American Journal of Community Psychology, 15, pp. 121-148. 